\title{
Ectopic Norrin Induces Growth of Ocular Capillaries and Restores Normal Retinal Angiogenesis in Norrie Disease Mutant Mice
}

\author{
Andreas Ohlmann, ${ }^{1}$ Michael Scholz, ${ }^{1}$ Andreas Goldwich, ${ }^{1}$ Bharesh K. Chauhan, ${ }^{2}$ Kristiane Hudl, ${ }^{3}$ Anne V. Ohlmann, ${ }^{1}$ \\ Eberhart Zrenner, ${ }^{3}$ Wolfgang Berger, ${ }^{4}$ Aleš Cvekl, ${ }^{2}$ Mathias W. Seeliger, ${ }^{3}$ and Ernst R. Tamm ${ }^{1}$ \\ ${ }^{1}$ Department of Anatomy, University of Erlangen-Nürnberg, D-91054 Erlangen, Germany, ${ }^{2}$ Departments of Ophthalmology and Visual Sciences and \\ Molecular Genetics, Albert Einstein College of Medicine, Bronx, New York 10461, ${ }^{3}$ Retinal Electrodiagnostics Research Group, University Eye Hospital \\ Department II, D-72076 Tübingen, Germany, and ${ }^{4}$ Institute of Medical Genetics, Division of Medical Molecular Genetics and Gene Diagnostics, University \\ of Zürich, CH-8603 Schwerzenbach, Switzerland
}

Norrie disease is an X-linked retinal dysplasia that presents with congenital blindness, sensorineural deafness, and mental retardation. Norrin, the protein product of the Norrie disease gene (NDP), is a secreted protein of unknown biochemical function. Norrie disease $\left(\mathrm{Nd} \mathrm{p}^{y /-}\right)$ mutant mice that are deficient in norrin develop blindness, show a distinct failure in retinal angiogenesis, and completely lack the deep capillary layers of the retina. We show here that the transgenic expression of ectopic norrin under control of a lens-specific promoter restores the formation of a normal retinal vascular network in $N d p^{y /-}$ mutant mice. The improvement in structure correlates with restoration of neuronal function in the retina. In addition, lenses of transgenic mice with ectopic expression of norrin show significantly more capillaries in the hyaloid vasculature that surrounds the lens during development. In vitro, lenses of transgenic mice in coculture with microvascular endothelial cells induce proliferation of the cells. Transgenic mice with ectopic expression of norrin show more bromodeoxyuridine-labeled retinal progenitor cells at embryonic day 14.5 and thicker retinas at postnatal life than wild-type littermates, indicating a putative direct neurotrophic effect of norrin. These data provide direct evidence that norrin induces growth of ocular capillaries and that pharmacologic modulation of norrin might be used for treatment of the vascular abnormalities associated with Norrie disease or other vascular disorders of the retina.

Key words: angiogenesis; retina; VEGF; PlGF; Norrie disease; Frizzled 4

\section{Introduction}

The vasculature of the retina is commonly used to study the mechanisms of primary vascular development and subsequent secondary remodeling, because abnormal vessel growth plays a central role in common human diseases such as retinopathy of prematurity, diabetic retinopathy, and age-related macular degeneration, all conditions that lead to severe visual impairment. In humans and mice, primary vascular development starts when vessels originate from the optic nerve head and spread over the surface of the retina to form a dense network (Connolly et al., 1988; Provis, 2001; Fruttiger, 2002). The formation of the primary vascular network in the retina is under the influence of tissue oxygenation and vascular endothelial growth factor (VEGF) released by astrocytes (Stone et al., 1995; Neufeld et al.,

Received Nov. 20, 2004; revised Dec. 28, 2004; accepted Dec. 28, 2004.

This work was supported by grants from the Glaucoma Research Foundation (San Francisco, CA) to E.R.T. and the Deutsche Forschungsgemeinschaft (SFB 539 and TP BI.4 to E.R.T. and Se837/4-1 to M.W.S.). We thank Kathrin Baier, Karin Göhler, Antonia Kellenberger, and Nadine Petersen for excellent technical help and Marco Gö $\beta$ wein for expert processing of the electron micrographs. We thank Aleš Cvekl Jr for his help with editing this manuscript.

Correspondence should be addressed to Ernst R. Tamm, Department of Anatomy, University of Regensburg, Universitätsstrasse 31, D-93040 Regensburg, Germany. E-mail: Ernst.Tamm@vkl.uni-regensburg.de. D01:10.1523/JNEUROSCI.4756-04.2005

Copyright $\odot 2005$ Society for Neuroscience $\quad$ 0270-6474/05/251701-10\$15.00/0
1999). From the primary vessels along the surface of the developing retina, new vessels start to sprout into deeper layers to form two capillary beds that ramify in the outer and inner plexiform layers of the retina (Connolly et al., 1988; Provis, 2001; Fruttiger, 2002). The factors that are required for angiogenic sprouting from the primary vascular network and the formation of the final capillary architecture of the retina differ from those that are involved in primary vascular development.

Among the factors that are required for the formation of deep retinal capillaries is norrin, a 131-amino acid-long, secreted protein with a cysteine-knot motif (Meitinger et al., 1993; Berger et al., 1996). Mutations in the Norrie disease gene (NDP) that encodes norrin cause Norrie disease, an X-linked retinal dysplasia, which presents with congenital or early childhood blindness (Berger et al., 1992; Meindl et al., 1992; Berger, 1998). In at least one-third of the cases, Norrie disease is accompanied by sensorineural deafness and some degree of mental retardation. Mutant mice with a targeted disruption of $N d p\left(N d p^{y /-}\right)$ show complete absence of intraretinal capillaries and a progressive loss of vessels within the stria vascularis of the cochlea (Richter et al., 1998; Rehm et al., 2002). The structural changes correlate with a marked loss of function, because mutant $N d p^{y /-}$ mice develop blindness (Ruether et al., 1997) and sensorineural deafness 
(Rehm et al., 2002). Norrin shows selective and high-affinity binding to frizzled-4 (Fz4) and induces activation of the classical Wnt pathway (Xu et al., 2004). Mutant mice that are deficient in fz4 show defects in the retina and stria vascularis that closely resemble those described in $N d p^{y /-}$ mutant mice (Xu et al., 2004). In humans, mutant frizzled-4 (FZD4) is responsible for autosomal-dominant familial exudative vitreoretinopathy, a developmental disorder characterized by incomplete vascularization of the peripheral retina (Robitaille et al., 2002).

To learn about the function or functions of norrin, we used the strategy of expressing ectopic norrin in the eye of transgenic mice by means of a strong lens-specific promoter. Here, we describe that ectopic norrin induces growth of ocular capillaries. In norrin-deficient $N d p^{y /-}$ mice, transgenic expression of ectopic norrin induces the formation of the deep retinal capillary layers and completely prevents the defects in retinal angiogenesis.

\section{Materials and Methods}

Generation and identification of $\beta B 1$-crystallin-norrin transgenic mice. The murine cDNA of norrin was excised from plasmid pBluescript SK ${ }^{-}$ (Berger et al., 1996) by an EcoRI and XhoI digest and cloned between the EcoRI and XhoI sites of plasmid pACP2 containing the simian virus 40 (SV40) poly(A) signal region and the SV40 small-T intron. A -434/+30 fragment of the chicken $\beta \mathrm{B} 1$-crystallin promoter was PCR amplified from plasmid pER17-5 (Flügel-Koch et al., 2002) using primers with $E c o$ RI and $\mathrm{XbaI}$ restriction sites at the ends. The promoter fragment was cloned between EcoRI and XbaI sites upstream from the sequences of the murine norrin $\mathrm{cDNA}$ to obtain plasmid $\mathrm{p} \beta \mathrm{B} 1$-norrin that was analyzed by automated sequencing (model 310; PE Applied Biosystems, Hayward, $\mathrm{CA})$. The microinjection construct was released from $\mathrm{p} \beta \mathrm{B} 1$-norrin by digestion with $\mathrm{XbaI}$ followed by gel electrophoresis. Microinjections and embryo transfers to obtain $\mathrm{FVB} / \mathrm{N} \beta \mathrm{B} 1$-crystallin-norrin transgenic mice were performed at the Transgenic Facility of the Albert Einstein College of Medicine (Bronx, NY). Potential $\beta$ B1-crystallin-norrin transgenic mice were screened by isolating genomic DNA from tail biopsies and testing for transgenic sequences by Southern blot hybridization and/or by PCR. Southern blot hybridization was performed using $10 \mu \mathrm{g}$ of XhoI-digested genomic DNA to determine copy number and number of integration sites. For PCR analysis, primers were used that span the promoter sequences to the norrin CDNA of the transgene. The sequences of the primers were $5^{\prime}$-ACACTGATGAGCTGGCACTTCCATT-3' and 5'-TGCATTCCTCACAGTGACAGGAG-3' (product length, $768 \mathrm{bp}$ ). The thermal cycle profile was denaturation at $94^{\circ} \mathrm{C}$ for $30 \mathrm{~s}$, annealing at $58^{\circ} \mathrm{C}$ for $30 \mathrm{~s}$, and extension at $72^{\circ} \mathrm{C}$ for $1 \mathrm{~min}$ for 30 cycles. Screening of Norrie disease (ND) mice with a targeted deletion of the Ndp gene was performed as described previously (Berger et al., 1996).

RNA analyses. Reverse transcription (RT)-PCR was used to amplify cDNA fragments of norrin, VEGF, placental growth factor (PlGF), Fz4, Fz5, Fz6, and Fz7. Sequences of primer pairs were 5' -AGCTCAAAGATGGTGCTCCT-3' and 5'-TAGAGCCAACAGGGGAAATG-3' for mouse norrin (product length, 495 bp), 5'-TCACCAAAGCCAGCACATAG-3' and $5^{\prime}$-AGGAATCCCAGAAACAACCC-3' for mouse VEGF (product length, $553 \mathrm{bp}$ ), 5'-ATTCAGTCCGTCCTGTGTCC-3' and 5'-GCAGGTTCTAGGCCTCCTCT-3' for mouse PlGF (product length, $633 \mathrm{bp}$ ), 5'-CGGCTACAACGTGACCAAGAT-3' and 5'-TGTGGTTGTGGTCGTTCTGTG-3' for human Fz4 (product length, 301 bp), 3'-CCCGAAGCAGTTTATCTTTGG-5' and 5'-CTGCGGTTGTAATCCATGC-3' for human Fz5 (product length, 624 bp), 5' -TTCTTCCTCTCGCAAATCTGG-3' and 5' -TATTGCAGGCTGTGCTATCGC-3' for human Fz6 (product length, $602 \mathrm{bp}$ ), and 5'-CTTATGCTCCATGTATGCGCC-3' and 5'AAAGTACATCAGGCCGTTGGC-3' for human Fz7 (product length, 432 bp). Total RNA from mouse eyes was used as a template for VEGF and PIGF cDNA fragments, whereas the norrin cDNA fragment was amplified using pBluescript $\mathrm{SK}^{-}$containing murine norrin cDNA as template. To identify frizzled receptors, total RNA from human dermal microvascular endothelial cells was used. RT was performed using Superscript II RT (Invitrogen, Karlsruhe, Germany). PCR for Norrie, VEGF, and PIGF was performed in a final volume of $50 \mu \mathrm{l}$ by initial denaturation at $94^{\circ} \mathrm{C}$ for $2 \mathrm{~min}$, followed by 35 cycles of $30 \mathrm{~s}$ at $94^{\circ} \mathrm{C}, 45 \mathrm{~s}$ of annealing at $55^{\circ} \mathrm{C}$, and $90 \mathrm{~s}$ of extension at $72^{\circ} \mathrm{C}$. The annealing temperature of PCR for frizzled receptors was $55^{\circ} \mathrm{C}$. Primers were used at a concentration of $10 \mathrm{pmol}$. After the last cycle, the extension time was $10 \mathrm{~min}$. PCR products were gel-purified by using the GFX PCR kit (Amersham Biosciences, Piscataway, NJ), cloned into pCR II-Topo (Invitrogen), and analyzed by automated sequencing.

After linearization of the vector with HindIII, antisense RNA probes for norrin, VEGF, and PIGF were generated and labeled with DIG-11UTP using T7-polymerase (Roche, Mannheim, Germany). For Northern blot analysis, total RNA was isolated using TRIzol (Invitrogen), separated on a $1 \%$ agarose gel containing $6 \%$ formaldehyde, and blotted onto a positively charged nylon membrane (Roche). After transfer, the blot was cross-linked using a UV Stratalinker 1800 (Stratagene, La Jolla, CA). Prehybridization was performed for $1 \mathrm{~h}$ at $60^{\circ} \mathrm{C}$ using the Dig EasyHybbuffer (Roche). After overnight hybridization at $60^{\circ} \mathrm{C}$, membranes were washed for 5 min with $2 \times$ SSC and $0.1 \%$ SDS at room temperature and 15 min with $0.2 \times$ SSC and $0.1 \%$ SDS at $70^{\circ} \mathrm{C}$. For detection of hybridization signals, membranes were blocked for $30 \mathrm{~min}$ at room temperature in $1 \%$ blocking reagent, $0.1 \mathrm{M}$ maleic acid, and $0.15 \mathrm{M} \mathrm{NaCl}, \mathrm{pH} 7.5$, and incubated $30 \mathrm{~min}$ in anti-digoxigenin-alkaline phosphatase diluted 1:10,000 (Roche). After washing membranes two times for $15 \mathrm{~min}$ in 0.1 M maleic acid, $0.15 \mathrm{M} \mathrm{NaCl}, \mathrm{pH} 7.5$, and $0.3 \%$ Tween 20 , chemiluminescence detection was performed (CDP-Star; Roche). The membranes were exposed using a Lumi-Imager (Roche). To monitor the integrity of RNA, the relative amounts of RNA loaded on the gel and the efficiency of transfer, membranes were stained with methylene blue. The intensity of the hybridization signal was determined by the Lumi-Analyst software (Roche).

Western blot analysis. Antibodies were developed by immunizing rabbits against the peptide sequence RPQTSKLKALRLRC corresponding to amino acids $97-110$ of mouse norrin. Affinity purification of antibodies was performed by chromatography using a protein A Sepharose column followed by a EAH Sepharose column (both Amersham Biosciences) to which the immunizing peptide had been linked with sulfosuccinimidyl 4-N-maleimidomethyl cyclohexane-1-carboxylate (Perbio Science, Erembodegem, Belgium) as a linker. Lenses were dissected from eyes of $\beta \mathrm{B} 1$-crystallin-norrin transgenic mice and wild-type littermates, lysed in SDS sample buffer, and centrifuged at $14,000 \times g$ for $10 \mathrm{~min}$. The supernatant was taken for gel analysis. Protein content was measured by using BCA protein assay reagent (Pierce, Rockford, IL). For one-dimensional Western blot analysis, the proteins $(5 \mu \mathrm{g})$ were boiled for $5 \mathrm{~min}$ and separated by tricine SDS-PAGE (Schägger and von Jagow, 1987) on a $10-17 \%(w / v)$ gradient-separating gel. After electrophoresis, the proteins were transferred with semidry blotting (Bio-Rad, Hercules, CA) on a polyvinyl difluoride membrane (Roche). The membrane was incubated with PBS containing $0.1 \%$ Tween 20 (PBST; pH 7.2) and 5\% bovine serum albumin for $1 \mathrm{~h}$. Affinity-purified polyclonal rabbit antibodies against norrin were added and allowed to react overnight at $4^{\circ} \mathrm{C}$; for negative control, the preimmune serum was used at the same concentration. After washing with PBST, an alkaline phosphatase-conjugated swine anti-rabbit IgG (1:2000; Dako Cytomation, Hamburg, Germany) was added for $30 \mathrm{~min}$. Visualization of the alkaline phosphatase was achieved by chemiluminescence. CDP-Star was diluted 1:100 in detection buffer, and the filters were incubated for $5 \mathrm{~min}$ at room temperature. Chemiluminescence was detected on a Lumi-Imager workstation (Roche).

Histology. Embryos were obtained from timed matings, with noon on the day of vaginal plug discovery designated as embryonic day 0.5 (E0.5). Heads (E13.5-E14.5) or eyes [postnatal day 2 (P2) to P21] were fixed for $24 \mathrm{~h}$ in $4 \%$ paraformaldehyde (PFA) and embedded in paraffin or in methacrylate (Technovit 7100; Hereaus Kulzer GmbH, Wehrheim, Germany). Paraffin $(7 \mu \mathrm{m})$ or methacrylate $(1.5 \mu \mathrm{m})$ sections were cut, placed on glass slides (SuperFrost/Plus; Menzel, Braunschweig, Germany), and stained with hematoxylin and eosin. Sagittal sections were analyzed by light microscopy (DMR; Leica Microsystems, Bensheim, Germany). For counts of capillaries in the tunica vasculosa lentis (TVL), all profiles of cross-sectioned capillaries were counted, and the number of capillary profiles per $100 \mu \mathrm{m}$ lens surface was calculated. For quanti- 
A

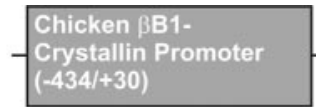

(464 bp)
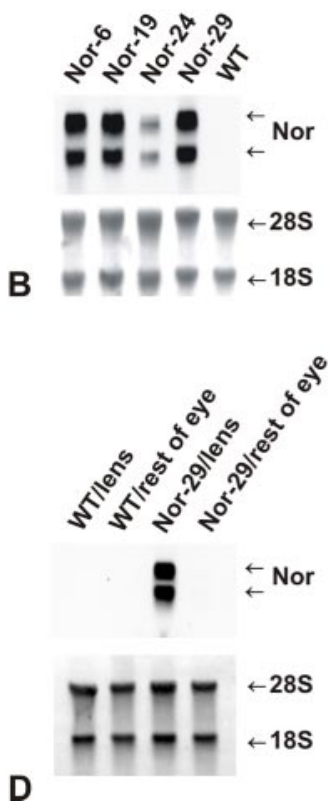

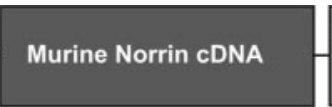

$(1.8 \mathrm{kB})$
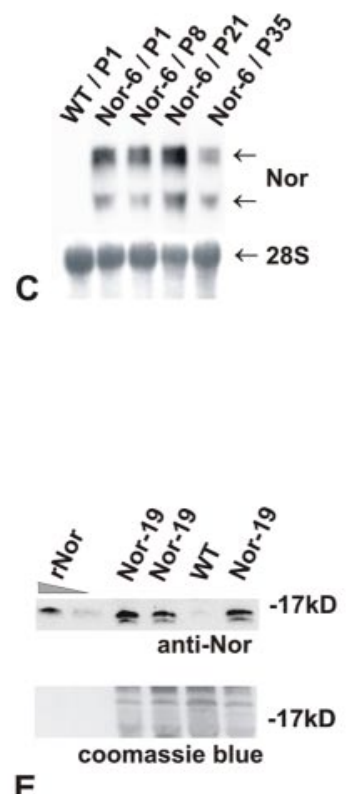

Figure 1. Generation of transgenic mice with ectopic expression of norrin. $A$, Drawing of the transgene. $B$, Northern blot analysis for transgenic mRNA in lenses from four transgenic lines (Nor-6, Nor-19, Nor-24, and Nor-29) and wild-type animals (WT). C, Northern blot analysis for transgenic mRNA in lenses from transgenic line Nor-6 at P1, P8, P21, and P35 and wild-type littermates (WT). D, Northern blot analysis for transgenic mRNA in lenses and eye tissue without lenses of transgenic line Nor-29 and wild-type littermates (WT) at P2. Ribosomal RNA was stained with methylene blue ( $B-D)$. E, SDS-PAGE (stained with Coomassie blue) and Western blot analysis for norrin in lenses from transgenic line Nor-19 and wild-type littermates (WT). As a positive control, murine recombinant norrin (rNor) was loaded. $F, G$, Immunostaining for transgenic norrin in wild-type (WT; $F$ ) and transgenic (Nor-29; G) lenses (Le) at E13.5. Scale bars, $10 \mu \mathrm{m}$.

tative analysis of retinal neurons at $\mathrm{P} 2$, nuclei were counted within an area of $50 \mu \mathrm{m}$ (nuclear cell layer) or $200 \mu \mathrm{m}$ (retinal ganglion cell layer) circumferential width at distance of $50 \mu \mathrm{m}$ to the optic nerve for counts of central retina, and at distance of $50 \mu \mathrm{m}$ from the ora serrata for peripheral retina. For quantitative analysis of retinal ganglion cells at P21, the number of cells per $50 \mu \mathrm{m}$ central retina was evaluated. For statistical analysis, a Student's $t$ test was performed.

Electron microscopy. For electron microscopy, eyes were placed in Ito's fixative (Ito and Karnovsky, 1968) for $24 \mathrm{~h}$ after the cornea had been pierced with a fine needle. The eyes were washed overnight in cacodylate buffer, postfixed with OsO4, dehydrated, and embedded in Epon (Roth, Karlsruhe, Germany). Semithin sections were stained with toluidine blue. Ultrathin sections were stained with uranyl acetate and lead citrate and viewed with a Zeiss (Oberkochen, Germany) EM 902 electron microscope.

Immunohistochemistry. Staining for norrin was performed using affinity-purified rabbit antibodies (1:50). As a negative control, preimmune serum was used. The localization of VEGF was studied with rabbit anti-VEGF antibodies (1:200; Santa Cruz Biotechnology, Santa Cruz, CA). PlGF was stained with rabbit anti-PlGF antibodies (1:200; R \& D Systems, Minneapolis, MN) and glial fibrillary acidic protein (GFAP) with rabbit anti-GFAP antibodies (Sigma, St. Louis, MO). For norrin staining, embryonic heads (E13.5-E14.5) were fixed in 4\% PFA overnight; for VEGF and PlGF labeling, eyes from P2 animals were fixed in $4 \%$ PFA for $4 \mathrm{~h}$; for GFAP labeling, eyes from p21 animals were fixed in $4 \%$ PFA overnight. NDP, VEGF, and PlGF immunoreactivity was visualized on frozen sections, whereas GFAP was stained on paraffin sections. Before overnight incubation at $4^{\circ} \mathrm{C}$ with the primary antibody, sections were incubated in Blotto's dry milk solution (Duhamel and Johnson,
1985) for $30 \mathrm{~min}$. The primary antibody was removed from the sections by three washes (10 min each) in PBS, and the sections were treated for $1 \mathrm{~h}$ with Alexa 488 Fluor antibodies (1:1000; Molecular Probes, Eugene, OR) or cyanine 3-conjugated secondary anti-rabbit antibodies (1:1000; Jackson ImmunoResearch, West Grove, PA). For visualization of retinal capillaries, paraffin sections were incubated overnight at $4^{\circ} \mathrm{C}$ with biotinylated Griffonia (bandeira) simplicifolia lectin I, isolectin B (1:100; Vector Laboratories, Burlingame, CA). After washing, the sections were incubated with streptavidinconjugated Alexa 488 Fluor (1:1000; Molecular Probes).

Bromodeoxyuridine labeling. Pregnant females were injected intraperitoneally with 10 mu 5-bromo-2'-deoxyuridine (BrdU; 1 ml/100 g body weight) $1 \mathrm{~h}$ before killing. Embryos (E13.5) were removed and processed for paraffin embedding. Sections were treated with 20 $\mathrm{mg} / \mathrm{ml}$ proteinase $\mathrm{K}$ for $10 \mathrm{~min}$, followed by $1.5 \mathrm{~N} \mathrm{HCl}$ for $30 \mathrm{~min}$ at room temperature. After incubation with Blotto's solution for $30 \mathrm{~min}$, the sections were treated overnight with monoclonal anti-BrdU Alexa Fluor 488-conjugated antibodies (Molecular Probes). Sagittal sections were analyzed by confocal microscopy. For quantitative analysis, the number of BrdUlabeled nuclei was counted in the central retina within an area of $100 \mu \mathrm{m}$ circumferential width.

Terminal deoxynucleotidyl transferasemediated biotinylated UTP nick end labeling. Apoptosis was detected by the terminal deoxynucleotidyl transferase-mediated biotinylated UTP nick end labeling (TUNEL) assay using the Apoptosis Detection System, Fluorescein (Promega, Madison, WI). Paraffin sections were treated with proteinase $\mathrm{K}(20 \mathrm{mg} / \mathrm{ml})$ for 10 $\mathrm{min}$ at room temperature, washed, fixed in $4 \%$ methanol-free formaldehyde solution for $5 \mathrm{~min}$, and covered with equilibration buffer. Terminal deoxynucleotidyl transferase buffer containing nucleotide mix was applied to the sections for $60 \mathrm{~min}$ at $37^{\circ} \mathrm{C}$ in a moist chamber. The sections were washed and counterstained with propidium iodide. For quantitative analysis, the number of TUNEL-positive nuclei throughout the entire retina was counted.

Confocal microscopy. Slides were processed for immunohistochemistry, BrdU, and TUNEL and viewed under a confocal microscope (MRC 1000; Bio-Rad, Cambridge, UK) with the appropriate filter settings for FITC (488 nm excitation; filter 522DF32; channel 2) and for propidium iodide or background fluorescence (568 nm excitation; filter 605DF32; channel 1). Channel 1 and channel 2 were coded red and green, respectively. Single optical sections of $1 \mu \mathrm{m}$ were created, electronically superimposed, and processed using Adobe Photoshop 7.0 (Adobe Systems, San Jose, CA).

Cell culture. Human dermal microvascular endothelial cells (HDMECs; Promocell, Heidelberg, Germany) were cultured in endothelial cell growth medium MV with supplement mix (Promocell). Confluent cell cultures were used for water-soluble tetrazolium salt (WST-1) cellproliferation assays. HDMECs were seeded onto 96-well cell-culture dishes (Corning, Corning, NY). After $1 \mathrm{~d}$, medium was changed, and cultures were incubated in $100 \mu \mathrm{l}$ of endothelial cell growth medium MV without supplement mix (Promocell). Intact lenses were dissected from transgenic mice and wild-type littermates (P2 and P7). Each lens was immediately placed in a well with HDMEC and cocultured under serumfree conditions. After $3 \mathrm{~d}$, lenses were removed, and the cells were incubated with the WST-1 (Roche, Mannheim, Germany) for $4 \mathrm{~h}$. Substrate 


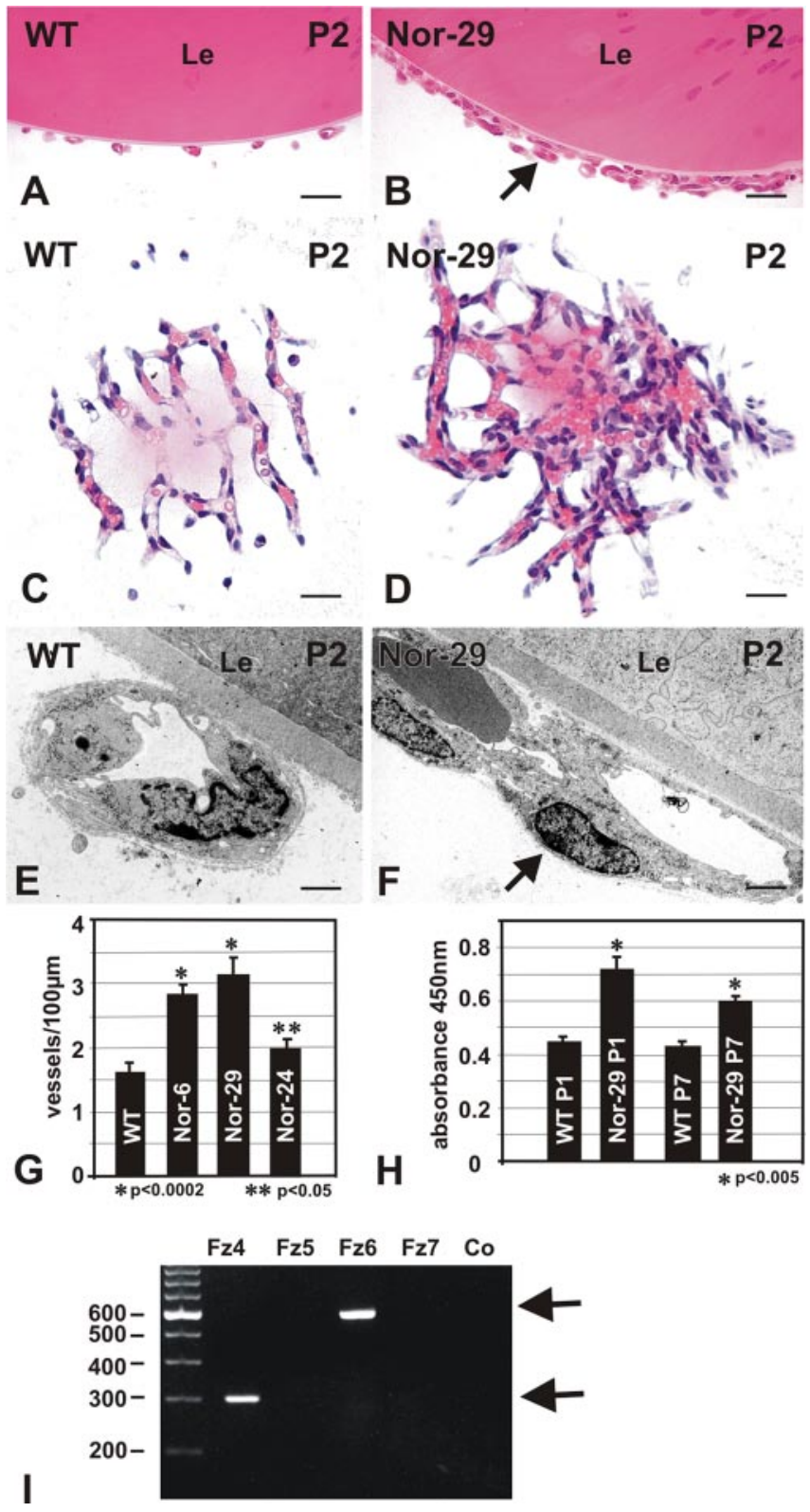

Figure 2. Ectopic norrin induces growth of ocular capillaries. $A-D$, Light microscopy of posterior lens (Le) and TVL in wild-type (WT; $A, C$ and Nor-29 transgenic $(B, D)$ mice at P2. Both sagittal $(A, B)$ and tangential $(C, D)$ sections are shown. In the TVL of transgenic mice, a marked increase in the number of capillaries is observed ( $B$, arrow). $E$, $F$, Electron microscopy of posterior lens (Le) and TVL capillaries in Nor-29 transgenic ( $F$ ) and wild-type (WT; $E$ ) mice. Capillaries in the TVL of transgenic animals are more numerous but otherwise show the same ultrastructural characteristics as those of wild-type animals and consist of an unfenestrated endothelium that is in contact with pericytes ( $F$, arrow). $G$, Quantitative analysis of the number of cross-sectioned capillaries (sagittal sections) in the TVL of lines Nor-6, Nor-29, and Nor-24 and wild-type littermates (WT) at P2 (mean \pm SEM, probability values as indicated). $H$, Proliferation of cultured HDMECs. Lenses of line Nor-29 were cocultured with HDMECs for $3 \mathrm{~d}$. After incubation, lenses were removed, and the proliferation was assessed by WST-1 assay (mean \pm SEM, probability values as indicated). I, RT-PCR for $\mathrm{F} z 4,5,6$, and $7 \mathrm{mRNA}$ in RNA from HDMECs. PCR products (arrows) were observed for Fz4 (301 bp) and Fz6 (602 bp). Scale bars: A, B, $20 \mu \mathrm{m} ; C, D, 10 \mu \mathrm{m}$; $E, F, 2 \mu \mathrm{m}$.

turnover was measured with an ELISA reader at $450 \mathrm{~nm}$ (Microplate Reader Benchmark; Bio-Rad).

Electroretinography. Electroretinograms (ERGs) were obtained according to procedures described previously (Seeliger et al., 2001). Mice were dark-adapted overnight before the experiments, and their pupils were dilated. Anesthesia was induced by subcutaneous injection of ket- amine $(66.7 \mathrm{mg} / \mathrm{kg})$ and xylazine $(11.7 \mathrm{mg} / \mathrm{kg})$. Silver needle electrodes served as reference (forehead) and ground (tail), and gold wire ring electrodes served as active electrodes. The ERG equipment consisted of a Ganzfeld bowl, a DC amplifier, and a personal computer-based control and recording unit (Toennies Multiliner Vision; Jaeger/Toennies, Höchberg, Germany). Bandpass filter cutoff frequencies were 0.1 and $3000 \mathrm{~Hz}$. Single flash recordings were obtained both under dark-adapted (scotopic) and light-adapted (photopic) conditions. Light adaptation was performed with a background illumination of $30 \mathrm{~cd} / \mathrm{m}^{2}$ presented for $10 \mathrm{~min}$. Stimuli were presented with increasing intensities, reaching from $10^{-4}$ to $25 \mathrm{~cd}^{\star} \mathrm{s} / \mathrm{m}^{2}$, divided into 10 steps of 0.5 and $1 \log \mathrm{cd}^{*} \mathrm{~s} / \mathrm{m}^{2}$. Ten responses were averaged with an interstimulus interval of 5 or $17 \mathrm{~s}$ (for $1,3,10,25 \mathrm{~cd}^{*} \mathrm{~s} / \mathrm{m}^{2}$ ).

\section{Results}

\section{$\beta$ B1-crystallin-norrin transgenic mice}

To assess the functional role of norrin, transgenic mice that express a $1.8 \mathrm{~kb}$ murine norrin $\mathrm{cDNA}$ driven to the lens by the chicken $\beta \mathrm{B} 1-$ crystallin promoter were generated. The chicken $\beta B 1-$ crystallin promoter $(-434 /+30)$ has been shown to drive lens-specific expression in transgenic mice and to be active in both primary and secondary lens fibers from E12.5 until adulthood in a copy number and position-independent manner (Duncan et al., 1995, 1996; Flügel-Koch et al., 2002). SV40 poly(A) sequences, including the SV40 small T-intron provided the polyadenylation signal (Fig. $1 A$ ). The $\beta \mathrm{B} 1$-norrin fragment was injected into pronuclear stage $\mathrm{FVB} / \mathrm{N}$ embryos to obtain transgenic mice. Four initial founder animals were identified by PCR and designated Nor-6, Nor-19, Nor-24, and Nor-29, respectively. Four independent transgenic families were produced with each founder animal, and Southern blot hybridization was performed to confirm that transgenic animals from each family contained a single transgene insertion site. Nine copies of the transgene were present in mice from line Nor-6, 10 in mice from line Nor-19, three in mice from line Nor-24, and 11 in mice from line Nor-29. The lenses and eyes of mice from transgenic lines Nor-6, Nor-19, and Nor-29 were $\sim 30 \%$ smaller than those of normal littermates or mice from line Nor-24. The corneas of all mice appeared to be normal and translucent after eye opening. Overall, the lenses of mice from lines Nor-6, Nor-19, and Nor-29 were clear, but contained hazy segmental spots, preferentially at their posterior poles. Animals from line Nor-24 had clear lenses, but started to develop a whitish mass behind the lens at 6 weeks of age. With increasing age, this mass grew in size and extended to the anterior parts of the eye.

Because the differences in phenotype suggested differences in the expression levels for the different transgenic integration sites, transgenic mRNA expression was analyzed by Northern blot hybridization. Two days postpartum (P2), total RNA was collected from lenses of all transgenic lines and control animals. Using a probe specific for mouse norrin, a strong hybridization signal was detected after 1 min exposure in RNA from lenses of lines Nor-6, Nor-19, and Nor-29 (Fig. 1B). A weaker signal was observed in RNA from lenses of line Nor-24, whereas no signal was observed in lenses from control animals. The signal corresponded to the expected transgene-specific norrin transcript of $\sim 1.8 \mathrm{~kb}$. In addition, a slower migrating band of similar intensity was observed, which probably corresponded to preprocessed mRNA. The time course of the transgenic expression was investigated in line Nor-6, in which norrin mRNA continued to be detectable until $\mathrm{P} 35$, although with somewhat weaker intensity than at P1, P8, and P21 (Fig. 1C). Based on the results of the Northern blot analysis, it was concluded that the differences in phenotype between individual lines result from higher transgenic norrin ex- 

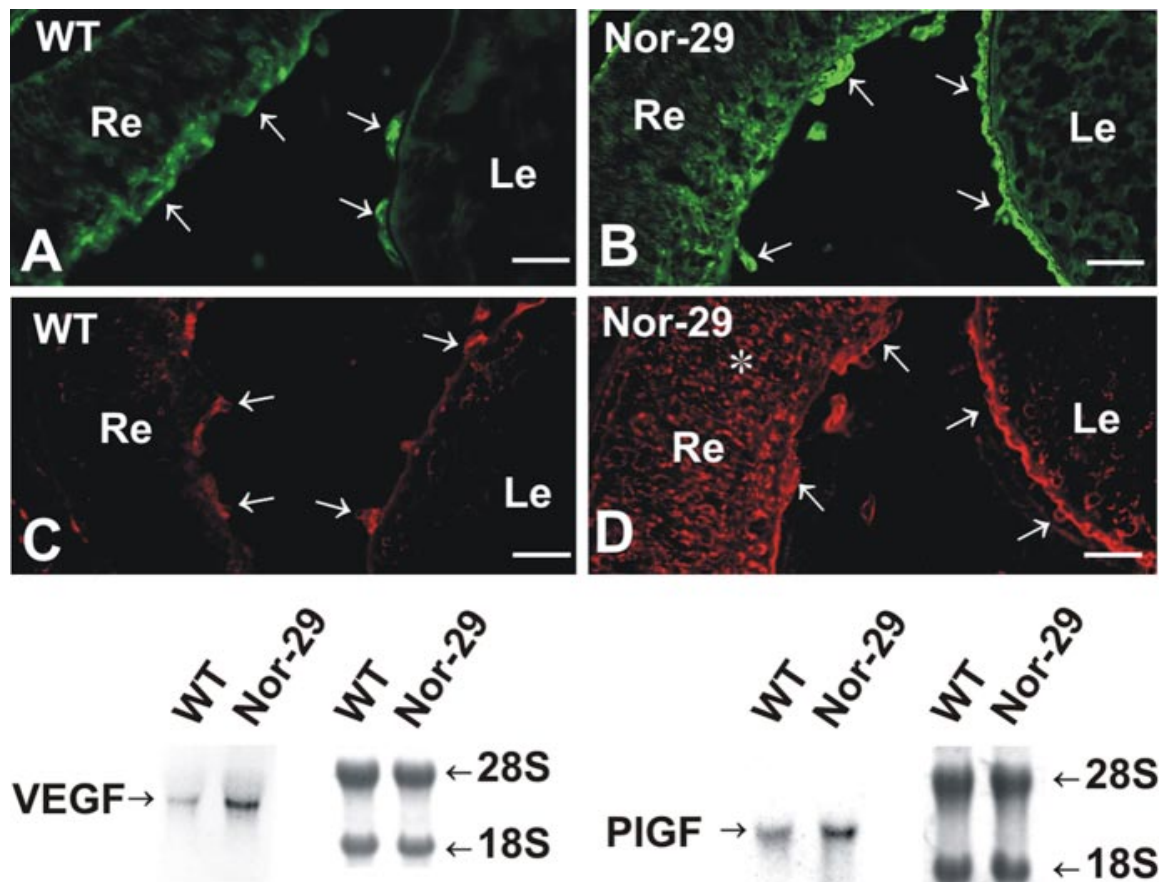

E
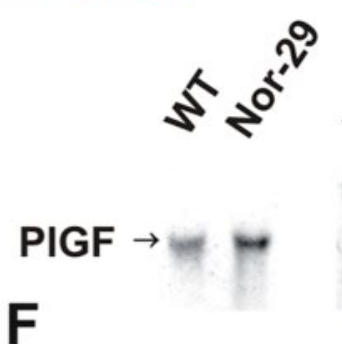

Figure 3. VEGF and PIGF expression is increased in mice with ectopic expression of norrin. $A-D$, Immunoreactivity for VEGF $(A, B)$ and PIGF $(C, D)$ in eyes of transgenic line Nor-29 $(B, D)$ and wild-type $(A, O)$ littermates at $P 2 . A, B$, In transgenic mice, VEGF immunoreactivity in TVL and inner retina (Re) is more intense (arrows) than in wild-type animals. C, D, In transgenic mice, PIGF immunoreactivity in TVL and retina (Re) is more intense (arrows) than in wild-type animals. E, F, Northern blot analysis for VEGF ( $E$ ) and PIGF ( $F$ ) mRNA in RNA from eyes of transgenic mice (Nor-29) and wild-type littermates (WT) at P2. Scale bars: A-D, $30 \mu \mathrm{m}$.

pression in lines Nor-6, Nor-19, and Nor-29, versus lower expression in line Nor-24.

To study whether the chicken $\beta \mathrm{B} 1$-crystallin promoter drives the expression of norrin mRNA as lens-specific, like that of other transgenes that have been expressed under control of this promoter (Duncan et al., 1996; Flügel-Koch et al., 2002), the expression of norrin mRNA in lenses of transgenic animals was compared with the expression in the rest of the eye. Northern blot experiments in transgenic animals at P2 showed an intense expression in RNA from the lens, but not in RNA from the rest of the eye (Fig. $1 D$ ). In wild-type animals, no signal for norrin was observed, neither in RNA from the lens nor in that from the rest of the eye (Fig. 1D).

To analyze whether transgenic mRNA was effectively translated, Western blot analysis was performed on lenses from Nor-19 animals and wild-type littermates using a peptide antibody against murine norrin. A major band at $15-16 \mathrm{kDa}$ was observed in immunoblots of proteins from transgenic lenses, which comigrated with recombinant norrin (Fig. $1 E$ ). In addition, a weaker band at $12-13 \mathrm{kDa}$ was observed in proteins from transgenic lenses, whereas no bands were observed in proteins from control lenses. Immunohistochemistry of the eyes of E14.5 embryos showed immunoreactivity for norrin in lenses of transgenic animals (Fig. 1G), whereas those of control littermates were essentially unstained (Fig. $1 F$ ).

The phenotype of animals from transgenic lines Nor-6, Nor24, and Nor-29 was subsequently analyzed from P1 to P21.

\section{Norrin induces vascular proliferation}

At P0-P2, transgenic mice with lens-specific ectopic expression of norrin showed a marked increase in the number of capillaries

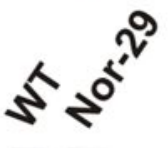

that surrounded the posterior surface of the lens (Fig. 2A-F). These capillaries form the TVL, which arises from the hyaloid artery during embryonic development and is still present in mice of this age. In wild-type animals, the posterior surface of the lens was in contact with a loose network of capillaries that were primarily arranged in parallel with spaces of $10-20 \mu \mathrm{m}$ between individual capillaries (Fig. 2A,C). In contrast, the posterior surface of the lens in transgenic animals was almost completely covered by a layer of tightly arranged capillaries that frequently overlapped each other (Fig. 2B,D). By electron microscopy, capillaries in the TVL of transgenic animals showed the same ultrastructural characteristics as those of wildtype animals and consisted of an unfenestrated endothelium that was in contact with pericytes (Fig. 2E,F). Quantitative analysis showed approximately twofold (line Nor-29) or 1.5-fold (line Nor-6) more cross-sectioned capillaries in the TVL of transgenic animals with high ectopic expression of norrin compared with wild-type littermates (Fig. 2G). This difference was statistically highly significant $(p<0.0002)$. A smaller $20 \%$ increase $(p<0.05)$ was observed in line Nor-24 with lower expression of transgenic norrin, indicating that the effect of norrin on capillaries in the TVL is dose dependent. In contrast to wildtype littermates, the hyaloid artery and the capillaries in the TVL did not regress and were present at least up until P21.

To see whether the effects of transgenic norrin on capillaries in the TVL are caused by a direct influence on proliferation of vascular endothelial cells, lenses of transgenic animals were added to monolayer cultures of confluent HDMECs. After $3 \mathrm{~d}$ of coculture under serum-free conditions, lenses were removed, and proliferation of HDMECs was analyzed by the WST-1 assay. Incubation of HDMECs with transgenic lenses from $\mathrm{P} 1$ animals resulted in a $66 \%(p<0.005)$ increase in proliferation, whereas incubation with P7 lenses caused a $40 \%$ increase $(p<0.005)$, indicating a stimulatory effect of norrin on growth of microvascular endothelial cells (Fig. $2 H$ ). The signaling effects of norrin appear to be mediated through specific binding to Fz4, a presumptive Wnt receptor (Xu et al., 2004). We therefore analyzed whether HDMECs express Fz4. By RT-PCR, mRNA of Fz4 could be detected along with that of Fz6, whereas Fz5 and Fz7 mRNA was not observed (Fig. 2I).

Because retinal and hyaloid vascular development in the posterior eye is under the influence of VEGF and PlGF (Neufeld et al., 1999; Feeney et al., 2003), we investigated whether the amounts of VEGF and/or PlGF are altered in mice with transgenic expression of ectopic norrin. By immunohistochemistry, immunoreactivity for both VEGF and PlGF was more intense in the TVL of transgenic animals compared with that of wild-type littermates (Fig. $3 A-D$ ). A parallel increase in immunoreactivity for VEGF and PlGF was observed in the inner layers of the retina. To assess the amounts of mRNA for VEGF and PlGF, Northern blot hybridization was performed on RNA from eyes of norrin transgenic mice and controls. mRNA for VEGF and PlGF was 
found in higher amounts in transgenic animals than in wild-type littermates (Fig. $3 E, F)$. The densitometric analysis of multiple experiments showed a $1.28 \pm 0.08$ increase in VEGF mRNA (mean \pm SEM; $n=6$ ) and a $1.26 \pm 0.08$ increase (mean \pm SEM; $n=4)$ in PlGF mRNA.

Ectopic norrin expression restores retinal structure and function in Norrie disease mice

$N d p$-deficient $\left(N d p^{y /-}\right)$ mice that do not express norrin show a distinct retinal phenotype that is characterized by the complete absence of the two intraretinal capillary beds and the formation of vascular membranes at the vitreal surface of the retina (Richter et al., 1998; Rehm et al., 2002). To learn whether the ectopic expression of norrin could prevent this phenotype and restore normal retinal vascular development and remodeling, $N d p^{y /-}$ mice were cross-bred with norrin overexpressing mice from line Nor-29. The phenotype of Nor-29/Nd $p^{y /-}$ mice was analyzed at P21, when the development of the retinal vasculature has been completed in the mouse eye and vessels have grown out from the primary vasculature within the nerve fiber layer to form a capillary bed in the outer plexiform layer and a second one in the inner plexiform layer (Connolly et al., 1988; Provis, 2001; Fruttiger, 2002). In Nor-29/Ndp $p^{y /-}$ animals, both retinal capillary beds were present and could be visualized by conventional light microscopy (Fig. 4A,C), electron microscopy (Fig. $4 E)$, and labeling of vascular endothelial cells with biotinylated $G$. (bandeira) simplicifolia lectin I (Fig. 4G). The capillaries showed the typical ultrastructural characteristics of retinal capillaries and were covered by pericytes and surrounded by a complete basal lamina (Fig. $4 E$ ). In contrast to Nor-29/Ndp $p^{y /-}$ animals, $N d p^{y /-}$ littermates expressed vascular membranes at the inner surface of the retina (Fig. $4 \mathrm{~B}$ ), whereas capillaries within the retinal layers were not observed (Fig. $4 \mathrm{H}$ ). In addition, focal strands and aggregates of cells were observed in $N d p^{y /-}$ animals, which resembled angiogenic sprouts and extended from the vascular membranes at the inner retinal surface to the inner plexiform layer and the outer surface of the inner nuclear layer (Fig. 4D), corroborating previous findings (Richter et al., 1998). By electron microscopy, no vascular lumen was observed in these cellular aggregates (Fig. $4 F)$. In summary, the ectopic transgenic expression of lens-derived norrin completely restored normal vascular development of the retina in $N d p^{y /-}$ mice.
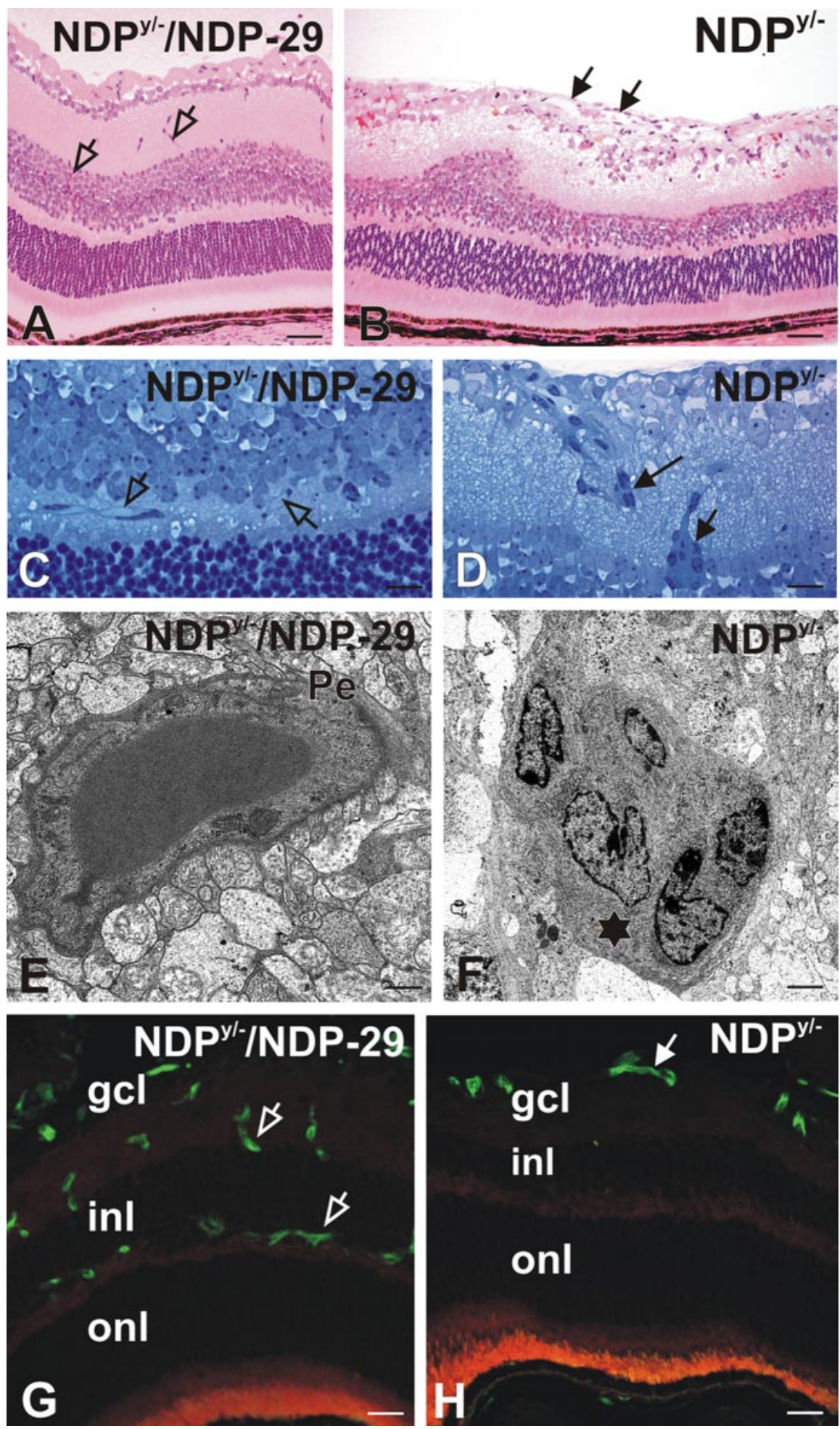

Figure 4. Ectopic transgenic norrin restores normal angiogenesis in $N d p^{y /-}$ mutant mice. $A-F$, Light $(A-D)$ and electron microscopy $(E, F)$ of $\mathrm{Ndp}^{y /-}$ mutant mice $(B, D, F)$ and $N d p^{y /-}$ mutant mice with ectopic expression of norrin (Nor-29/Ndp ${ }^{y /-} ; A$, $C, E)$ at P21. $A, C, E$, In Nor-29/Ndp ${ }^{y /-}$ mice, capillaries are seen in both inner ( $A$, arrows) and outer (C, arrows) plexiform layers. By electron microscopy $(E)$, the capillaries express the typical ultrastructural characteristics of retinal capillaries and are covered by pericytes ( $\mathrm{Pe}$ ) and surrounded by a complete basal lamina (arrows). $B, D, F, \ln N d p^{y /-}$ mutant mice, the surface of the retina is covered by a dense vascular membrane ( $B$, arrows), whereas no capillaries are observed in deeper layers of the retina. Angiogenic sprouts extend from the vascular membranes at the inner retinal surface to the inner plexiform layer ( $D$, arrows). By electron microscopy, no vascular lumen is observed in the angiogenic sprouts (F). G, H, Staining of vascular endothelial cells in Nor-29/ $N d p^{y /-}(G)$ and $N d p^{y /-}(H)$ mice with biotinylated G. (bandeira) simplicifolia lectin I. In Nor-29/Ndp ${ }^{y /-}$ eyes, capillaries are positively labeled on the retinal surface and in both inner and outer plexiform layers (arrows). gcl, Ganglion cell layer; inl, inner nuclear layer; onl, outer nuclear layer. Scale bars: $A, B, G, H, 20 \mu \mathrm{m} ; C, D, 8 \mu \mathrm{m} ; E, F, 2 \mu \mathrm{m}$. 

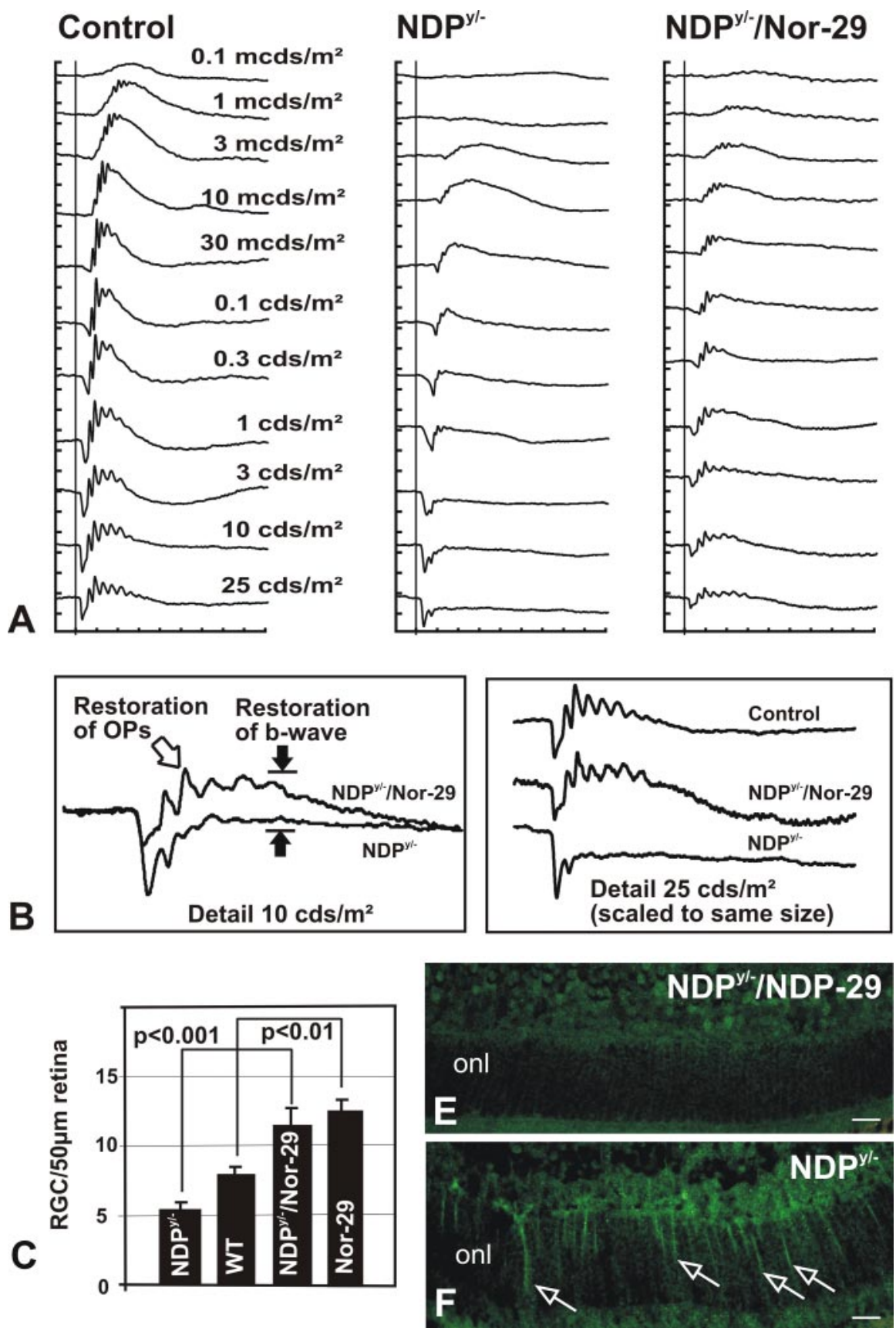

Figure 5. Ectopic transgenic norrin restores normal retinal function in $N d p^{y /-}$ mutant mice. $A, B$, Electrophysiological analysis. $A$, Exemplary scotopic ERG intensity series illustrating the differences between wild-type controls, Ndp ${ }^{y /-}$ animals, and Nor-29/ $N d p^{y /-}$ mice. B, ERG waveform details. Left, Comparison of the ERG of $N d p^{y /-}$ and Nor- $29 / \mathrm{Ndp}^{y /-}$ mice recorded at $10 \mathrm{~cd}{ }^{*} \mathrm{~s} / \mathrm{m}^{2}$. Right, Comparison of the ERG waveforms recorded at $25 \mathrm{~cd}{ }^{*} \mathrm{~s} / \mathrm{m}^{2}$ scaled to equal size. Although the ERG in the transgenic animals is generally smaller, presumably because of the reduced eye size, the typical hypoxia features seen in Ndp-deficient mice have disappeared in the Nor-29/Ndp ${ }^{y /-}$, and the normal waveform is remarkably restored. C, Morphological analysis of RGC number per $50 \mu \mathrm{m}$ central retina in $N d p^{y /-}$, Nor-29/Ndp ${ }^{y /-}$, and wild-type (WT) animals. Ndp ${ }^{y /-}$ mice show less RGCs than wild-type littermates (mean \pm SEM, probability values as indicated). D, E, Immunostaining for GFAP in the central retina of Nor-29/Ndp ${ }^{y /-}$ mice with ectopic expression of norrin $(D)$ and in $N d p^{y /-}$ animals $(E)$. In $N d p^{y /-}$ mice, immunoreactivity for GFAP is seen in Müller glia (arrows), indicative of retinal stress (E). In contrast, no GFAP labeling is observed in Müller cells of NDP-29/Ndp $p^{y /-}$ mice (D). onl, Outer nuclear layer. Scale bars: $D, E, 12 \mu \mathrm{m}$.

To investigate whether the restoration of the inner retinal vasculature also caused an improvement of retinal function, ERGs were performed. Similar to previous findings (Ruether et al., 1997), dark-adapted ERGs in $N d p^{y /-}$ mice showed a dramatic loss of the positive b-wave (Fig. 5A,B), which is mostly shaped by the neurons of the inner retina, particularly the bipolar cells. In addition, no substantial oscillatory potentials, a set of higher frequency wavelets usually superimposed on the b-wave, were observed. The changes in ERG waveforms in $N d p^{y /-}$ mice closely matched those obtained in normal eyes in a state of retinal hypoxia (Tazawa and Seaman, 1972). In particular, the almost complete loss of oscillatory potentials together with the subtotal reduction of the b-wave (a so-called negative ERG) are characteristic findings. In contrast, in NDP-29/Ndp ${ }^{y /-}$ mice, both the positive b-wave as well as the oscillatory potentials were completely restored (Fig. 5A,B). The overall amplitude in NDP-29/Ndp $p^{y /-}$ mice was lower than in wild-type controls, which we attributed to the reduced size of the globe in NDP-29 animals (Möller et al., 2004). Together, our findings show that the restoration of the inner retinal vasculature is associated with extensive rescue of retinal function.

$N d p^{y /-}$ mice have been reported to show a continuous loss of retinal ganglion cells, which starts at P7 (Richter et al., 1998). This loss of ganglion cells was also observed in our study, in which less retinal ganglion cells per $50 \mu \mathrm{m}$ central retina were found in P21 Ndp $p^{y /-}$ animals compared with wild-type littermates (Fig. 5C). In contrast, Nor-29/Ndp $p^{y /-}$ mice of the same age contained the same amount of retinal ganglion cells per $50 \mu \mathrm{m}$ central retina as NDP-29 animals (Fig. 5C) and significantly more ganglion cells as $N d p^{y /-}$ animals $(p<0.001)$.

In $N d p^{y /-}$ mice, we observed increased levels of GFAP in Müller glia, indicative of retinal stress (Fig. 5D). In contrast, no GFAP labeling was observed in Müller cells of NDP-29/Nd $p^{y /-}$ mice, indicating that retinal stress had been treated by the presence of ectopic norrin and the resulting restoration of retinal structure and function (Fig. 5E).

\section{Norrin induces growth of retinal} neurons during development

While comparing the number of retinal ganglion cells between $N d p^{y /-}$ mice and both Nor-29/Ndp ${ }^{y /-}$ and Nor-29 mice, we observed that the number of ganglion cells in Nor-29/Ndp ${ }^{y /-}$ and Nor-29 mice was not only higher than that of $N d p^{y /-}$ animals, but also significantly higher than in wild-type littermates $(p<0.01)$ (Fig. 5C). We therefore wondered whether the ectopic expression of norrin might have a direct stimulatory effect on proliferation of retinal ganglion cells. To assess this question, we performed BrdU labeling of Nor-29 embryos at E14.5 when ectopic norrin can be detected in the transgenic lens and proliferation of retinal progenitor cells is high (Cepko et al., 1996). The quantitative evaluation showed significantly more BrdU-positive 

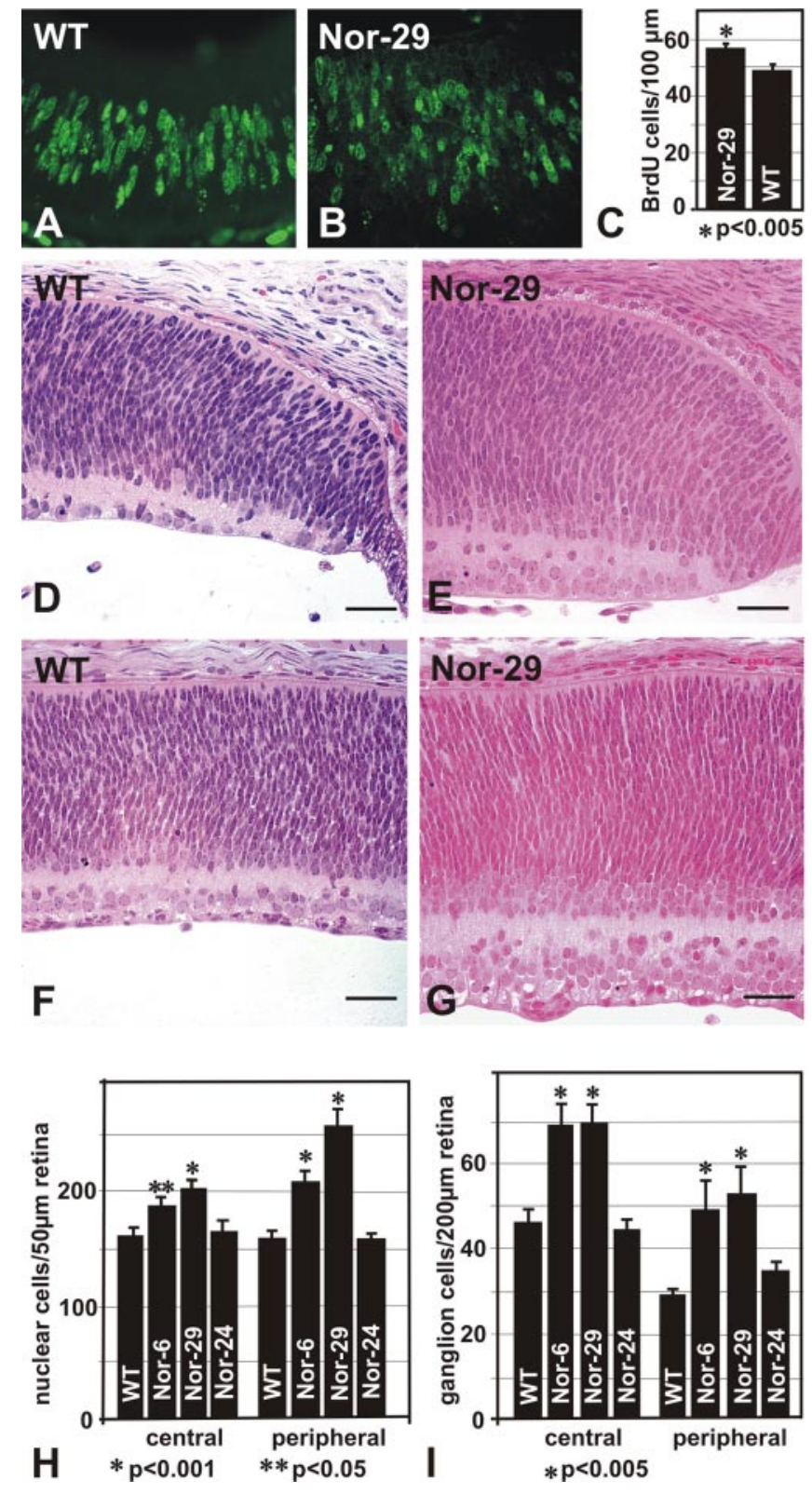

Figure 6. Increase in proliferation of retinal progenitor cells and retinal thickness in mice with ectopic expression of norrin. $A, B$, BrdU labeling of transgenic (TG) mice from line Nor-29 $(A)$ and wild-type (WT) littermates ( $B$ ) atE14.5. C, Quantitative evaluation of BrdU-labeled cells per $100 \mu \mathrm{m}$ central retina in Nor-29 and wild-type (WT) animals (mean \pm SEM, probability values as indicated). $D-G$, Light microscopy of peripheral $(D, E)$ and central $(F, G)$ retina in transgenic (TG) mice from line Nor-29 $(E, G)$ and wild-type (WT) littermates $(D, F)$. In Nor-29 animals, both the central and peripheral retina is markedly thicker than in wild-type animals. $H$, I, Quantitative analysis of the number of cells per $50 \mu \mathrm{m}$ (nuclear layer, $H$ ) or $200 \mu \mathrm{m}$ (ganglion cell layer, I) of transgenic lines Nor-6, Nor-29, Nor-24, and wild type (WT) littermates at P2 (mean \pm SEM, probability values as indicated). Scale bars: $A, B, 10 \mu \mathrm{m} ; D-G, 20 \mu \mathrm{m}$.

cells in the retina of Nor-29 animals as in wild-type littermates, indicating a growth stimulatory effect of norrin on retinal cells (Fig. 6A-C). The increased proliferation of retinal cells resulted in a thicker peripheral (Fig. 6D,E) and central retina (Fig. 6F,G) of transgenic animals at $\mathrm{P} 2$ compared with wild-type littermates. The quantitative analysis showed that the increase in thickness was caused by a higher number of cells in both nuclear and ganglion cell layers per $50 \mu \mathrm{m}$ (nuclear cell layer) or $200 \mu \mathrm{m}$ (ganglion cell layer) of central or peripheral retina (Fig. $6 \mathrm{H}, \mathrm{I}$ ). This difference was statistically significant in two lines with relatively high expression of ectopic norrin (Nor-6 and Nor-29). However, no significant increase was observed in line Nor-24 with lower expression of transgenic norrin, indicating that the effect of norrin on growth of developing retinal neurons is dose dependent. Because the increase in retinal thickness could be related to reduced apoptosis of retinal ganglion cells caused by the presence of ectopic norrin, TUNEL was performed at P7, when developmental apoptosis in the retina is at its peak (Young, 1984). No significant differences in the number of labeled cells were found between mice from line Nor-29 and wild-type littermates (data not shown).

\section{Discussion}

We conclude that ectopic norrin, which is expressed in and secreted from the lens is completely sufficient to prevent the defects in retinal structure and function that are seen in $N d p^{y /-}$ mutant mice. This conclusion is based on (1) the lens-specific expression of norrin and its mRNA, (2) the restoration of a normal retinal vascular network including the presence of deep intraretinal capillaries in both outer and inner plexiform layers of $N d p^{y /-}$ mice, which express transgenic norrin in their lenses (Nor-29/Ndp $p^{y /-}$ mice), and (3) the presence of a normal ERG with a positive b-wave in Nor-29/Nd $p^{y /-}$ mice, which indicates that the restoration in retinal vasculature correlates with that of retinal function.

The results of this study were made possible by the fact that ectopic norrin secreted from the lens reached the retina in amounts that were sufficient to promote proper retinal angiogenesis. This finding appears to be in contrast with in vitro data, in which secreted norrin was tightly associated with the extracellular matrix and the spatial extent of the diffusion of norrin was limited (Perez-Vilar and Hill, 1997; Xu et al., 2004). A possible explanation for this discrepancy between in situ and in vitro observations might be a difference in the quality of the respective extracellular matrices. Perez-Vilar and Hill (1997) observed that heparin sulfate, heparin, and heparinase have no effect on norrin binding and concluded that proteoglycans are not involved in the strong binding of norrin to the extracellular matrix of COS-7 cells in vitro (Perez-Vilar and Hill, 1997). Indeed, proteoglycans are a major component of the extracellular matrix between retinal cells (Inatani and Tanihara, 2002), whereas fibrillar components are very limited or absent. Similar to proteoglycans, norrin might also show limited binding to hyaluronan in the developing vitreous humor.

It is of interest to note that ectopic norrin restored the retinal vascular network by completely respecting the normal vascular architecture of the retina, whereas no abnormal vascular sprouting or signs of retinal neovascularization were observed. On the contrary, the formation of abnormal dense vascular membranes that are found at the inner surface of $N d p^{y /-}$ mice (Richter et al., 1998) was completely prevented. This observation is in marked contrast to findings in transgenic animal models, in which other signaling molecules that are involved in retinal angiogenesis were ectopically expressed. Expression of VEGF in photoreceptors under control of the rhodopsin promoter stimulated sprouting of neovascularization from the deep capillary bed of the retina (Okamoto et al., 1997; Tobe et al., 1998). The new vessels in $r$ /VEGF animals grew abnormally between photoreceptors and invaded the subretinal space. The same promoter was used to drive transgenic expression of platelet-derived growth factor- $B$ (PDGF-B), which is required for proper investment of retinal capillaries with pericytes (Lindahl et al., 1997). Rho/PDGF-B mice showed a marked hyperproliferation of pericytes, endothelial cells, and astrocytes, and they developed traction retinal de- 
tachment (Vinores et al., 2003). In marked contrast to VEGF and PDGF-B, norrin appears to be selectively involved in those cellcell signaling events that are required for the formation of a higher-order vascular architecture and that occur during late stages of vascular patterning in the retina.

The restoration of the normal vascular architecture appears to be completely sufficient to restore retinal function, as evidenced by ERG. We hypothesize that the loss of both b-wave and oscillatory potentials, which we observed in $N d p^{y /-}$ animals is mainly, if not exclusively, caused by a severe neuronal dysfunction caused by the lack of oxygen in the inner layers of the retina. Indeed, a very similar ERG pattern has been described after retinal vascular occlusion in humans and in animal models of selective retinal hypoxia (Tazawa and Seaman, 1972). Our hypothesis differs from that of Ruether et al. (1997), who investigated $N d p^{y /-}$ animals and observed similar changes as we did in the present study, but interpreted those as correlates of a schisis-like alteration of the retina. No structural schisis that may affect transmission from photoreceptors to bipolar cells or the bipolar cells themselves was observed in this or other studies on $N d p^{y /-}$ mice (Berger et al., 1996; Richter et al., 1998). In addition, recent data from a mouse model of juvenile $x$-linked retinoschisis (Weber et al., 2002) show that even in the presence of a structural schisis that causes a comparable loss of the b-wave, the oscillatory potentials are much less affected than in $N d p^{y /-}$ mice.

The effects of ectopic norrin on capillary growth are not restricted to retinal capillaries, but are also observed in capillaries of the second vascular tree in the posterior eye, the hyaloid vasculature that is transiently present during eye development. In the normal mouse eye, hyaloid vessels form a well organized vascular network at birth, which starts to regress at P4 and completely disappears at P16 (Ito and Yoshioka, 1999). We assume that in transgenic animals at P2, the increased density of hyaloid vessels in the TVL next to the lens a site of ectopic norrin expression is caused by a positive influence of ectopic norrin on growth of hyaloid capillaries. This assumption is supported by the in vitro data of this study, which show that transgenic lenses induce proliferation of microvascular endothelial cells. Effects on growth of hyaloid vessels have also been observed in transgenic mice with lens-specific overexpression of VEGF-A (Ash and Overbeek, 2000). The hyaloid vessels in VEGF-A overexpressing mice were reported to be poorly organized at P0, with large dilated lumenlike structures and unusually thin walls. In contrast, our data show that hyaloid vessels in newborn mice with ectopic expression of norrin are more numerous than in the wild-type, but otherwise express essentially all ultrastructural characteristics of well differentiated hyaloid capillaries. This finding supports our concept of a role for norrin in signaling events during the formation of a well differentiated higher-order vascular architecture. At present, we do not know whether norrin alone is capable of inducing growth of ocular capillaries or whether the simultaneous presence of additional factors is needed. Putative candidates are VEGF and/or PlGF, because we found both factors to be increased in retina and TVL of mice with ectopic expression of norrin. The hyaloid artery and the TVL does not regress in transgenic mice, which we attribute to the fact that ectopic norrin continues to be expressed from the lenses of the animals until at least P35. Interestingly, a persistence of hyaloid vessels has also been observed in $N d p^{y /-}$ mice lacking norrin (Richter et al., 1998; Ohlmann et al., 2004) and $f z 4^{-1-}$ mice lacking its receptor (Xu et al., 2004). We agree with others that the most likely explanation of this finding is an increase in VEGF production by the hypoxic retina, caused by the lack of intraretinal capillaries, which promotes survival of hyaloid vessels (Xu et al., 2004).

Ectopic norrin does not only restore normal capillarization of the retina, but it also prevents the progressive loss of retinal ganglion cells (RGCs) seen in $N d p^{y /-}$ mutant mice, which becomes significant at approximately P14 (Richter et al., 1998). A likely explanation is that hypoxia induces RGC death in $N d p^{y /-}$ mice, and restoration of retinal capillaries caused by the presence of ectopic norrin maintains normal oxygenation of the retina. Still, a direct neurotrophic effect of norrin on retinal neurons should be considered, because its receptor Fz4 is strongly expressed in neurons of brain and retina (Wang et al., 2001). $f \mathrm{z}^{-/-}$mice show progressive cerebellar degeneration with widespread granule cell death beginning at P14, an age at which the vasculature still appears to be normal (Wang et al., 2001; Xu et al., 2004). Our finding of an increase in thickness of RGC and granular cell layers in P2 mice with ectopic expression of norrin appears to support the hypothesis of neurotrophic activity of norrin, although the increase in thickness might also be a mechanism to compensate for the smaller size of transgenic eyes. Still, we also found a significant increase in the number of BrdU-labeled retinal progenitor cells in transgenic animals at E14.5, when eyes from both wild-type and transgenic animals are still of similar size. The increase in VEGF expression that is seen in eyes with ectopic expression of norrin might contribute to the increase in retinal progenitor cell proliferation, because VEGF has been found to stimulate growth of photoreceptor cells in vitro (Yourey et al., 2000). In addition, the pharmacologic inhibition of VEGF activity by specific antagonists in newborn mice, which still have avascular retinas at this age, was shown to cause a significant decrease in retinal thickness (Robinson et al., 2001).

An intriguing aspect supported by the data of the present work is that pharmacologic modulation of norrin might be used for treatment of the vascular abnormalities associated with Norrie disease or other vascular disorders of the retina. The expression of the receptor of norrin, Fz4, has been found in cultured human dermal microvascular endothelial cells in our study and in endothelial cells from adult lung capillaries isolated ex vivo (Favre et al., 2003), indicating that ectopic norrin and Fz4 signaling could also be used for treatment of vascular disorders outside the eye.

\section{References}

Ash JD, Overbeek PA (2000) Lens-specific VEGF-A expression induces angioblast migration and proliferation and stimulates angiogenic remodeling. Dev Biol 223:383-398.

Berger W (1998) Molecular dissection of Norrie disease. Acta Anat (Basel) 162:95-100.

Berger W, van de PD, Warburg M, Gal A, Bleeker-Wagemakers L, de Silva H, Meindl A, Meitinger T, Cremers F, Ropers HH (1992) Mutations in the candidate gene for Norrie disease. Hum Mol Genet 1:461-465.

Berger W, van de PD, Bachner D, Oerlemans F, Winkens H, Hameister H, Wieringa B, Hendriks W, Ropers HH (1996) An animal model for Norrie disease (ND): gene targeting of the mouse ND gene. Hum Mol Genet 5:51-59.

Cepko CL, Austin CP, Yang X, Alexiades M, Ezzeddine D (1996) Cell fate determination in the vertebrate retina. Proc Natl Acad Sci USA 93:589-595.

Connolly SE, Hores TA, Smith LE, D’Amore PA (1988) Characterization of vascular development in the mouse retina. Microvasc Res 36:275-290.

Duhamel RC, Johnson DA (1985) Use of nonfat dry milk to block nonspecific nuclear and membrane staining by avidin conjugates. J Histochem Cytochem 33:711-714.

Duncan MK, Roth HJ, Thompson M, Kantorow M, Piatigorsky J (1995) Chicken $\beta \mathrm{B} 1$ crystallin: gene sequence and evidence for functional conservation of promoter activity between chicken and mouse. Biochim Biophys Acta 1261:68-76. 
Duncan MK, Li X, Ogino H, Yasuda K, Piatigorsky J (1996) Developmental regulation of the chicken $\beta \mathrm{B} 1$-crystallin promoter in transgenic mice. Mech Dev 57:79-89.

Favre CJ, Mancuso M, Maas K, McLean JW, Baluk P, McDonald DM (2003) Expression of genes involved in vascular development and angiogenesis in endothelial cells of adult lung. Am J Physiol Heart Circ Physiol 285:H1917-H1938.

Feeney SA, Simpson DA, Gardiner TA, Boyle C, Jamison P, Stitt AW (2003) Role of vascular endothelial growth factor and placental growth factors during retinal vascular development and hyaloid regression. Invest Ophthalmol Vis Sci 44:839-847.

Flügel-Koch C, Ohlmann A, Piatigorsky J, Tamm ER (2002) Overexpression of TGF- $\beta 1$ alters early development of cornea and lens in transgenic mice. Dev Dyn 225:111-125.

Fruttiger M (2002) Development of the mouse retinal vasculature: angiogenesis versus vasculogenesis. Invest Ophthalmol Vis Sci 43:522-527.

Inatani M, Tanihara H (2002) Proteoglycans in retina. Prog Retin Eye Res 21:429-447.

Ito M, Yoshioka M (1999) Regression of the hyaloid vessels and pupillary membrane of the mouse. Anat Embryol (Berl) 200:403-411.

Ito S, Karnovsky MJ (1968) Formaldehyde-glutaraldehyde fixatives containing trinitro compounds. J Cell Biol 39:168A-169A.

Lindahl P, Johansson BR, Leveen P, Betsholtz C (1997) Pericyte loss and microaneurysm formation in PDGF-B-deficient mice. Science 277:242-245.

Meindl A, Berger W, Meitinger T, van de PD, Achatz H, Dorner C, Haasemann M, Hellebrand H, Gal A, Cremers F (1992) Norrie disease is caused by mutations in an extracellular protein resembling C-terminal globular domain of mucins. Nat Genet 2:139-143.

Meitinger T, Meindl A, Bork P, Rost B, Sander C, Haasemann M, Murken J (1993) Molecular modelling of the Norrie disease protein predicts a cystine knot growth factor tertiary structure. Nat Genet 5:376-380.

Möller A, Eysteinsson T, Steingrímsson E (2004) Electroretinographic assessment of retinal function in microphthalmia mutant mice. Exp Eye Res 78:837-848.

Neufeld G, Cohen T, Gengrinovitch S, Poltorak Z (1999) Vascular endothelial growth factor (VEGF) and its receptors. FASEB J 13:9-22.

Ohlmann AV, Adamek E, Ohlmann A, Lütjen-Drecoll E (2004) Norrie gene product is necessary for regression of hyaloid vessels. Invest Ophthalmol Vis Sci 45:2384-2390.

Okamoto N, Tobe T, Hackett SF, Ozaki H, Vinores MA, LaRochelle W, Zack DJ, Campochiaro PA (1997) Transgenic mice with increased expression of vascular endothelial growth factor in the retina: a new model of intraretinal and subretinal neovascularization. Am J Pathol 151:281-291.

Perez-Vilar J, Hill RL (1997) Norrie disease protein (norrin) forms disulfide-linked oligomers associated with the extracellular matrix. J Biol Chem 272:33410-33415.

Provis JM (2001) Development of the primate retinal vasculature. Prog Retin Eye Res 20:799-821.

Rehm HL, Zhang DS, Brown MC, Burgess B, Halpin C, Berger W, Morton CC, Corey DP, Chen ZY (2002) Vascular defects and sensorineural deafness in a mouse model of Norrie disease. J Neurosci 22:4286-4292.

Richter M, Gottanka J, May CA, Welge-Lüssen U, Berger W, Lütjen-Drecoll E
(1998) Retinal vasculature changes in Norrie disease mice. Invest Ophthalmol Vis Sci 39:2450-2457.

Robinson GS, Ju M, Shih SC, Xu X, McMahon G, Caldwell RB, Smith LE (2001) Nonvascular role for VEGF: VEGFR-1, 2 activity is critical for neural retinal development. FASEB J 15:1215-1217.

Robitaille J, MacDonald ML, Kaykas A, Sheldahl LC, Zeisler J, Dube MP, Zhang LH, Singaraja RR, Guernsey DL, Zheng B, Siebert LF, Hoskin-Mott A, Trese MT, Pimstone SN, Shastry BS, Moon RT, Hayden MR, Goldberg YP, Samuels ME (2002) Mutant frizzled-4 disrupts retinal angiogenesis in familial exudative vitreoretinopathy. Nat Genet 32:326-330.

Ruether K, van de Pol D, Jaissle G, Berger W, Tornow RP, Zrenner E (1997) Retinoschisislike alterations in the mouse eye caused by gene targeting of the Norrie disease gene. Invest Ophthalmol Vis Sci 38:710-718.

Schägger H, von Jagow G (1987) Tricine-sodium dodecyl sulfate-polyacrylamide gel electrophoresis for the separation of proteins in the range from 1 to $100 \mathrm{kDa}$. Anal Biochem 166:368-379.

Seeliger MW, Grimm C, Stahlberg F, Friedburg C, Jaissle G, Zrenner E, Guo $\mathrm{H}$, Reme CE, Humphries P, Hofmann F, Biel M, Fariss RN, Redmond TM, Wenzel A (2001) New views on RPE65 deficiency: the rod system is the source of vision in a mouse model of Leber congenital amaurosis. Nat Genet 29:70-74.

Stone J, Itin A, Alon T, Pe'er J, Gnessin H, Chan-Ling T, Keshet E (1995) Development of retinal vasculature is mediated by hypoxia-induced vascular endothelial growth factor (VEGF) expression by neuroglia. J Neurosci 15:4738-4747.

Tazawa Y, Seaman AJ (1972) The electroretinogram of the living extracorporeal bovine eye. The influence of anoxia and hypothermia. Invest Ophthalmol 11:691-698.

Tobe T, Okamoto N, Vinores MA, Derevjanik NL, Vinores SA, Zack DJ, Campochiaro PA (1998) Evolution of neovascularization in mice with overexpression of vascular endothelial growth factor in photoreceptors. Invest Ophthalmol Vis Sci 39:180-188.

Vinores SA, Seo MS, Derevjanik NL, Campochiaro PA (2003) Photoreceptor-specific overexpression of platelet-derived growth factor induces proliferation of endothelial cells, pericytes, and glial cells and aberrant vascular development: an ultrastructural and immunocytochemical study. Brain Res Dev Brain Res 140:169-183.

Wang Y, Huso D, Cahill H, Ryugo D, Nathans J (2001) Progressive cerebellar, auditory, and esophageal dysfunction caused by targeted disruption of the frizzled-4 gene. J Neurosci 21:4761-4771.

Weber BH, Schrewe H, Molday LL, Gehrig A, White KL, Seeliger MW, Jaissle GB, Friedburg C, Tamm E, Molday RS (2002) Inactivation of the murine $\mathrm{X}$-linked juvenile retinoschisis gene, Rslh, suggests a role of retinoschisin in retinal cell layer organization and synaptic structure. Proc Natl Acad Sci USA 99:6222-6227.

Xu Q, Wang Y, Dabdoub A, Smallwood PM, Williams J, Woods C, Kelley MW, Jiang L, Tasman W, Zhang K, Nathans J (2004) Vascular development in the retina and inner ear: control by Norrin and Frizzled-4, a high-affinity ligand-receptor pair. Cell 116:883-895.

Young RW (1984) Cell death during differentiation of the retina in the mouse. J Comp Neurol 229:362-373.

Yourey PA, Gohari S, Su JL, Alderson RF (2000) Vascular endothelial cell growth factors promote the in vitro development of rat photoreceptor cells. J Neurosci 20:6781-6788. 